\title{
Sobreviver ou viver melhor?
}

\section{Surviving or living better?}

Hermann Voesgen-Wieczorek

Professor de Gestão do Trabalho Cultural, vice-presidente de Assuntos Internacionais e comissário para assuntos interculturais da University of Applied Sciences, Postdam, Alemanha. Doutorado em Ciências Sociais pela Carl-von-Ossietzky University Oldenburg e membro do comitê de cultura de Potsdam. E-mail: voesgen@fh-potsdam.de

\section{APRESENTAÇÃO POR LIANA BRITO'}

O dilema dos refugiados é uma questão antiga da história da humanidade. Na atualidade, ele permanece presente com particularidades próprias das contradições de um tempo de grande avanço no desenvolvimento das possibilidades humanas concretas. A conferência do Professor Hermann Voesgen, aqui publicada, nos convida a percorrer um pouco desta realidade, hoje, na Alemanha. O professor apresenta, inicialmente, o conceito de imigrantes e refugiados, tendo como base o contexto histórico europeu, ontem e hoje, embora se trate de uma questão também presente na América Latina. Nosso papel, na academia, não se encerra no questionar e nomear as problemáticas humanas, mas consiste

\footnotetext{
1 Professora da UECE, no bacharelado em Serviço Social e no Mestrado Acadêmico em Serviço Social, Trabalho e Questão Social. Pós-doutorado na University of Applied Sciences, Postdam, Alemanha com a temática de desenvolvimento, desigualdades e movimentos sociais. Possui graduação em Serviço Social pela UECE, mestrado em Educação pela Universidade Federal de São Carlos (UFSCar) e doutorado em Educação pela UFC, com Estágio de Doutoramento (Bolsa Sanduiche) na Universidade de Warwick, Inglaterra.
} 
também em tomá-las como substâncias da nossa prática coletiva, na construção de relações sociais que ampliem as possibilidades humano-genéricas.

O autor destaca de forma rica as estratégias de enfrentamento da questão dos imigrantes por parte do governo, da universidade e de grupos ativistas na Alemanha. Seu texto nos apresenta a centralidade da solidariedade, como uma relação vivida por aqueles que assumem a coragem de estar com os refugiados e, com eles, construírem uma maneira de viver melhor. Voesgen compartilha a sua experiência com os estudantes na sua universidade, revelando a capacidade criativa de abertura de novos espaços para os refugiados. São construções coletivas numa demonstração de que a tolerância, o respeito e a solidariedade são práticas humanas necessárias para construção de um viver melhor.

Finalmente, agradecemos o apoio financeiro da Coordenação de Aperfeiçoamento de Pessoal de Nível Superior (CAPES) e da Fundação Cearense de Apoio ao Desenvolvimento Científico e Tecnológico (FUNCAP), ${ }^{2}$ que garantiram a vinda do professor doutor Hermann Voesgen.

\section{INTRODUÇÃO ${ }^{3}$}

Este texto é uma versão revisada de uma conferência de mesmo nome que fiz na UECE, em outubro de 2018. Nele, objetivo delinear uma visão sobre a atual discussão e o desenvolvimento da política de refugiados na Europa, especialmente na Alemanha.

Primeiramente, tentarei esclarecer alguns termos relacionados a este tópico. Em seguida, retratarei brevemente acerca da história das migrações de refugiados na Alemanha, após a Segunda Guerra Mundial. Na parte principal do texto, falarei sobre os desdobramentos da crise de refugiados, na Alemanha, após 2015, ou seja,

2 Edital 05/2014 - CAPES-MEC/FUNCAP-SECITECE - Proc. No. 88887.099783/2015-01, do Mestrado em Serviço Social, Trabalho e Questão Social, em parceria com o Programa de Pós-Graduação em Sociologia, ambos da UECE.

3 A tradução do alemão para o português do texto revisado pelo autor foi realizada por Loli Stender. 
no contexto atual. Utilizando o exemplo da minha universidade, a Universidade de Ciências Aplicadas de Potsdam, apresentarei um projeto de integração para refugiados, em contraste a movimentos populistas e xenófobos que levam a uma crescente polarização da sociedade europeia. Finalmente, abordarei algumas perspectivas para uma sociedade inclusiva.

\section{FORMAS DE MIGRAÇÃO}

Utilizando a palavra imigração como termo geral, será feita uma distinção abrangente entre imigração legal e ilegal. A imigração legal está ligada ao desejo deum país de recrutar pessoas como trabalhadores, para promover o desenvolvimento econômico. A fim de orientar os processos de migração no interesse do respectivo país, são emitidas regras que determinam o número de imigrantes, por ano, e as formações profissionais das pessoas a serem recebidas. Um exemplo bem conhecido é a atual política de imigração do Canadá, baseada em um catálogo detalhado de critérios de entrada, com um sistema de pontuação para os imigrantes.

A República Federativa da Alemanha, fundada após a Segunda Guerra Mundial, em 1948, até recentemente não se considerava um país de imigração; por isso, existiam poucas possibilidades de se imigrar legalmente para o país, tendo sido dificultadas a imigração e a aquisição da cidadania alemã, desde então. Durante muito tempo, não havia interesse econômico na imigração, pois havia imigrantes suficientes dos antigos territórios alemães e da República Democrática Alemã (RDA). A situação era diferente nas antigas potências coloniais europeias, como a França e a Grã-Bretanha (em menor escala, também na Holanda). Nestes países, pessoas das ex-colônias tiveram a oportunidade de se estabelecerem na respectiva e antiga "pátria-mãe". Com o passar do tempo, estas opções legais foram restringidas por causa das capacidades de integração limitadas pelas economias em questão.

Devido às crescentes restrições à imigração legal, o número de imigrantes ilegais aumentou e estas pessoas formaram seus próprios meios socioculturais nas cidades. Enquanto as diferenças na vida econômica e social ainda são tão profundas como 
atualmente, entre muitos países africanos e a Europa, haverá sempre pessoas tentando cruzar fronteiras sem permissão.

Na França, o movimento da sociedade civil conhecido como Sans Papiers chama a atenção para a situação miserável das pessoas sem direito à residência. Essas pessoas são econômica e socialmente exploradas, vivendo em constante medo da descoberta de sua condição ilegal e da deportação. O objetivo do movimento Sans Papiers é a legalização dos imigrantes secretos, para que tenham documentos oficiais. Este exemplo mostra que a questão do que é considerado legal ou ilegal é objeto de debate político. Os ativistas franceses citam razões humanitárias para a legalização, opondo-se a uma política de imigração baseada unicamente em critérios econômicos. Existe um slogan popular na Alemanha, que diz: "nenhum ser humano é ilegal". Da mesma maneira que os SansPapiers, ele questiona o poder de decisão de países rejeitarem pessoas nas fronteiras.

Um processo de legalização da imigração, provavelmente único em seu tamanho, ocorre dentro da União Europeia (UE). Cidadãos de todos os países da UE podem se estabelecer e trabalhar em país dessa comunidade internacional. Para isso, não precisam apresentar solicitação nenhuma, há liberdade de escolher o lugar onde morar e trabalhar. Sendo assim, por exemplo, todos os portugueses podem se mudar para Berlim, procurar trabalho lá e vice-versa. Isso levou, nos últimos anos, a fortes movimentos migratórios, do sul e leste da Europa à Europa central, à Grã-Bretanha e à Escandinávia.

Um terceiro tipo de migrantes são as pessoas que moram em outro país por um tempo determinado. Isso inclui estudantes, que vão para o exterior por um semestre ou para um curso inteiro; funcionários de empresas internacionais, que trabalham temporariamente fora do país; como também funcionários de organizações internacionais. Há também aposentados que escolhem passar a velhice em um país climaticamente agradável. Existem ainda outras possibilidades para a migração temporária. Num mundo globalizado, movimentos migratórios estão se tornando um fator cada vez mais relevante para os respectivos países. 
Motivos e consequências deste desenvolvimento não cabem no contexto do nosso tema de hoje.

A quarta categoria de migrantes são os refugiados: pessoas que têm que deixar seus países, porque estão sendo perseguidas, temem por suas vidas e/ou não suportam mais uma situação social e política específica. Eles não querem emigrar, mas buscam refúgio com a esperança de retornarem mais tarde à sua terra natal. O reconhecimento legal do Estatuto de Refugiado e o direito de residência associado são regulados pela Convenção das Nações Unidas sobre Refugiados e pelas respectivas leis nacionais de asilo. Os refugiados que solicitam asilo na Alemanha devem comprovar que estão sendo perseguidos e ameaçados como indivíduos. Necessariamente, realizam-se estudos de cada caso. Faz-se uma avaliação política da situação do solicitante o que influencia substancialmente as decisões do governo alemão. Este avalia regularmente a situação de perigo em certos países, para saber se existe perseguição e ameaça.

No caso do Afeganistão, por exemplo, atualmente o governo alemão classifica grande parte do país como seguro. Por conseguinte, não há justificativa para garantir asilo a refugiados de lá e, portanto, é difícil para pessoas vindas do Afeganistão serem reconhecidas como refugiadas. Em contrapartida, devido à guerra civil na Síria, quase todos os refugiados daquele país receberam, pelo menos, uma proteção temporária e o direito de residência na Alemanha. O direito de asilo é temporário, limitado inicialmente por três anos, mas podendo ser prorrogado. Se o motivo da emigração ainda permanece no final do prazo estabelecido, é possível obter o direito permanente de residência e a posterior naturalização.

Na maioria dos países europeus, a imigração legal é muito restrita. Para pessoas pouco qualificadas, ela é quase impossível. Portanto, pessoas de países pobres estão tentando entrar na promissora Europa solicitando asilo político. Há, portanto, uma mistura de pedidos de imigração para melhorar a qualidade de vida, com fugas por motivo de perseguição política, religiosa e étnica. Este assim chamado "abuso" do direito de asilo é uma questão política polêmica na Alemanha e em muitos outros países 
europeus. Até agora, os países europeus ainda não conseguiram estabelecer uma posição uniforme em relação à questão dos refugiados, que seguem sem uma resposta aos seus pedidos. Como criar um equilíbrio entre a missão humanitária e o objetivo de impedir a imigração descontrolada?

\section{MOVIMENTOS MIGRATÓRIOS NA EUROPA}

Impossível contar, aqui e agora, a longa história das migrações na Europa. Nas escolas europeias, toda criança aprende sobre "migrações de povos", depois do colapso do Império Romano. Na continuação, é ensinada como a mistura de povos rearranjou-se. Ao longo da história, outras migrações e deslocamentos de fronteiras se seguiram. Podemos citar, por exemplo, como, no século XIX, a industrialização provocou movimento em massa das regiões rurais para os novos centros industriais, como no Ruhrgebiet, no ocidente da Alemanha. Naquela região do centro-oeste da Alemanha, hoje em dia, cerca de um terço dos habitantes tem nome polonês.

Após a Segunda Guerra Mundial, ocorreu uma ampla redistribuição de territórios e habitantes: a Alemanha perdeu um terço do seu território no leste. Como resultado, mais de 10 milhões de pessoas tiveram que fugir para os territórios alemães remanescentes. Este era um grande desafio para o país devastado e empobrecido pela guerra, o que foi superado mediante cessão disciplinada e alocação de habitações, bem como por meio de racionamento de alimentos. Além disso, os refugiados receberam apoio financeiro, para que pudessem construir um novo sustento para assuas vidas.

A integração foi alcançada também graças a uma impressionante recuperação econômica e revitalização da indústria, o chamado "milagre econômico", daquela época. Isso resultou em uma grande demanda por mão de obra que foi satisfeita, em parte, por meio da imigração da RDA, que estava sob o controle da União Soviética e onde foi introduzida uma economia socialista planejada. A prosperidade econômica, no entanto, desenvolveu-se muito mais rapidamente na Alemanha Ocidental. Essa prosperidade, combinada com as liberdades individuais, as quais sofreram 
severas limitações na parte oriental da Alemanha, era incentivo para muitas pessoas da RDA fugirem para a Alemanha Ocidental. Até agosto de 1961, mais de 3 milhões de pessoas haviam se mudado da Alemanha Oriental para a Ocidental. A construção do Muro de Berlim e uma fronteira à prova de fuga, ao longo de todas as duas partes da Alemanha, interromperam o fluxo de migração.

As empresas, então, recrutaram trabalhadores de outros países para impulsionar o crescimento econômico. Centenas de milhares de trabalhadores, predominantemente do sexo masculino, foram recrutados no sul da Europa, sobretudo, na Turquia. Era previsto que eles ficassem na Alemanha por alguns anos e, depois, voltassem aos seus países. Estes trabalhadores eram chamados trabaIhadores convidados, com o objetivo de sublinhar o caráter temporário da sua estadia. A ideologia, mencionada acima, de que a Alemanha não era país de imigração, foi mantida mesmo em face desta imigração em massa de trabalhadores.

Havia ainda outros grupos de imigrantes: o maior deles eram os chamados alemães provenientes da Rússia, que se referiam a pessoas da antiga União Soviética, cujos antepassados emigraram da Alemanha para a Rússia e viviam lá em suas próprias áreas de assentamentos. Com a crise da União Soviética, mais de 1 milhão destas pessoas, etnicamente alemães, vieram para a Alemanha Ocidental. Graças ao princípio de ius sanguini (em oposição a ius solis), que existiu até a virada do milênio, estes descendentes tinham o direito de vir para a Alemanha, embora muitos deles mal conseguissem falar alemão. Eram, então, estrangeiros que, primeiramente, tiveram que encontrar suas maneiras de se integrarem à sociedade alemã.

A situação dos trabalhadores convidados se desenvolveu também de forma diferente do planejado: a maioria deles ficou na Alemanha e levou suas famílias consigo. O resultado desse processo migratório são comunidades de origem turca, a serem encontradas em quase todas as cidades alemãs. Como o governo e a grande parte da sociedade, durante muito tempo, continuaram a defender que a Alemanha não era país de imigração, as tarefas necessárias para a integração, tais como o ensino de língua, o 
atendimento em jardins de infância e escolas, a oferta de integração cultural, etc., foram negligenciadas.

Esta situação mudou apenas a partir de 1989, com o primeiro Governo Federal composto por uma coalizão entre socialdemocratas e ambientalistas. A transformação da sociedade em um mundo globalizado tornou-se tema central da atuação governamental. Por conseguinte, a Alemanha era, por um lado, técnica e emocionalmente bem preparada para as ondas de refugiados a partir de 2015. Por outro lado, a rejeição e o medo de estranhos, que haviam sido promovidos durante muito tempo por representantes do campo político conservador, ainda eram terrivelmente fortes, especialmente na Alemanha Oriental.

\section{A CRISE DE REFUGIADOS}

Como resultado da guerra civil na Síria, milhões de pessoas fugiram para os países vizinhos, como Líbano, Jordânia e Turquia. Como as condições de vida também não eram muito boas nestes países, muitas pessoas queriam continuar a fuga até chegarem à Europa Central e ao Norte europeu. Lá eles esperavam encontrar melhores condições de vida e perspectivas para um novo começo. Como resultado desses processos, cerca de 1 milhão de pessoas chegaram à Alemanha em 2015.

Para essa situação, o termo crise de refugiados foi estabelecido na Alemanha. É possível diferenciar três tipos de crise. No começo, ela era humanitária e a chanceler alemã, Ângela Merkel, decidiu abrir a fronteira, porque a situação dos refugiados na Hungria não era mais aceitável, do ponto de vista humanitário. Os refugiados da Síria chegaram a pé, após ter caminhado cerca de 6.000 quilômetros, desde a Hungria, e já tendo vivenciado coisas terríveis ao longo do caminho, como rejeições, violência, etc. A Hungria não estava disposta a aceitar esses refugiados ou, pelo menos provisoriamente, fornecer alimentos, banheiros e abrigo. Os sírios, portanto, ficaram nas ruas da Hungria e todas as noites tínhamos que assistir fotos dessa catástrofe humana na televisão. A decisão histórica da chanceler alemã de abrir as fronteiras foi um grande gesto humano contra a política de rejeição praticada por muitos 
países europeus. A abertura da fronteira para os refugiados era acompanhada por uma "cultura de acolhida", da qual participaram muitas pessoas, realizando numerosas ações voluntárias.

O afluxo de tantas pessoas, em pouco tempo, representou grande desafio para administrações, autoridades de migração, cidades e outras instâncias. Os refugiados precisavam ser cuidados, abrigados, registrados e seus pedidos de asilo, processados. Essa tremenda tarefa de gerenciamento e controle foi amplamente administrada com grande comprometimento e responsabilidade. Em um nível prático, instituições e voluntários mostraram que a promessa da chanceler Merkel $^{4}$ era realista. No entanto, ainda é controverso se será possível conseguir este feito no nível social e da vida comunitária, pois é um processo com resultado em aberto. O forte aumento de pessoas de outras culturas, com hábitos cotidianos desconhecidos e, frequentemente, crenças muçulmanas, é visível em todas as cidades. Muitas pessoas consideram estas mudanças negativas ou, pelo menos, críticas.

Depois da primeira fase, quando a cultura de boas-vindas era muito presente, as atitudes negativas e céticas tornaram-se mais fortes. Os três elementos de crise continuam sendo motivo de preocupação para discussões sociais e políticas na Alemanha. Eu voltarei a isso no final da minha apresentação.

Gostaria de destacar, no entanto, em primeiro lugar, a maneira prática de lidar com a imigração nesta grande escala. A Alemanha parece ter aprendido com os seus erros, quando lhe faltava uma política de integração e com as consequências respectivas. O objetivo global era agora "fazer melhor desta vez" e apoiar, desde o início, a integração das pessoas que estavam chegando. Houve e ainda existem muitas atividades e programas voltados para esta questão, organizados pelo Governo Federal, pelos estados, pelas autoridades locais e por instituições.

É pré-requisito para programas adequados conhecer a origem e as condições socioculturais específicas dos refugiados, a fim de

4 À época, a promessa da chanceler alemã de abrigar os refugiados sírios era lembrada pela sua fala "Nós conseguiremos fazer isso", nos meios de comunicação e entre a sociedade política e civil. 
não considerá-los um grupo homogêneo. Em termos de origem, as pessoas da Síria representam o maior grupo. Eles vêm de diferentes estratos sociais, possuem orientações religiosas e seculares diferentes e também diversos níveis de educação. Cerca de 20\% dos refugiados sírios têm uma formação acadêmica. Outro grupo fortemente representado são os afegãos. Eles são em sua maioria homens, jovens e solteiros. Há também refugiados do Iraque, já por muitas décadas. Chegam, de vez em quando, pessoas com um bom nível de formação do Irã. Nos últimos anos, pessoas de países africanos estão, cada vez mais, tentando chegar à Europa. Embora haja grande instabilidade política em seus países, para muitos destes refugiados, o foco está nas dificuldades econômicas. As chances de eles receberem asilo político são mais baixas do que aquelas dos grupos mencionados anteriormente.

Vamos falar agora do trabalho prático de integração que tem sido feito na Alemanha, desde 2015. Existe um amplo serviço de assessoria para treinamento e colocação profissional. Postos de trabalho específicos foram criados para esta finalidade. Todos os refugiados reconhecidos têm direito a cursos de línguas oferecidos por diferentes instituições. Para certos grupos, como adolescentes solteiros e mulheres solteiras, foram criados programas de atendimentos especiais. Em muitas cidades, tenta encontrar, o mais rápido possível, apartamentos em bairros onde há pessoas nativas, para que os refugiados não passem muito tempo nas acomodações compartilhadas.

\section{PREPARAR REFUGIADOS PARA ESTUDOS ACADÊMICOS}

A seguir, gostaria de falar mais detalhadamente dos esforços de universidades para preparar estudantes imigrantes interessados em estudar. Como exemplo, citarei os programas para refugiados da University of Applied Sciences de Potsdam, pelos quais fui responsável.

Já em 2015, ficou claro para a maioria das universidades que elas queriam e deveriam contribuir para a integração dos refugiados. Sabia-se que entre os sírios (o maior grupo de refugiados), uma proporção considerável seria preparada para iniciar estudos 
acadêmicos. Inicialmente, pensou-se que cerca de 10\% deles teriam o nível de formação adequado, depois ficou claro que quase $20 \%$ o tinham. Portanto, as faculdades começaram a desenvolver programas para preparar os refugiados para os estudos, oferecendo, ao mesmo tempo, cursos intensivos de alemão. Quem providenciou o financiamento para tais programas foram os estados federais, por serem responsáveis pelas universidades. O Serviço Alemão de Intercâmbio Acadêmico (DAAD), financiado pelo Governo Federal, forneceu fundos para os cursos de idioma.

$\mathrm{Na}$ minha universidade em Potsdam, sendo vice-presidente para assuntos internacionais, tomei a iniciativa e desenvolvi um serviço interno para aconselhamento e assistência aos refugiados, visando a fornecer a melhor preparação possível para que eles ingressassem no ensino superior. Sob o nome Higher Education for Refugees (HERE!), foi criado um centro de assessoria para os refugiados que desejassem cursar a faculdade. Duas funcionárias foram contratadas para isso e, além disso, contratou-se um número flexível de assistentes acadêmicos que falasse árabe ou farsi. A consulta realizada pelo centro HERE! acontece em três etapas:

i. Triagem: verificam-se quais os estudos universitários que seriam interessantes para esta pessoa ou se poderiam ser mais adequadas outras opções de carreira. Analisam-se também a formação anterior dos refugiados interessados e as suas perspectivas profissionais.

ii. Análise contextual: investigam-se as condições de vida e de residência da pessoa em questão; se ele/ela receberá direito de permanência no país; se existem possibilidades de financiamento acadêmico mediante empréstimo estudantil, etc.

iii. Orientação: informam aos refugiados sobre o sistema de ensino superior, sobre os cursos oferecidos, comparando-os com as condições e experiências que tiveram em seus países de origem.

Aos refugiados que, após a consulta ao HERE! , decidem estudar na University of Applied Sciences de Potsdam, oferecemos cursos 
preparatórios para o ingresso nas disciplinas e cursos de alemão que acontecem em paralelo, visando ajudar os participantes a passarem, com sucesso, dentro de um ano, no exame de alemão, que é necessário para a inscrição no ensino superior. Atualmente, pela quarta vez, estes cursos preparatórios e de idiomas estão sendo realizados. A cada ano, cerca de 1/3 dos participantes consegue a inscrição universitária, no final da fase preparatória. Por isso, podemos dizer que o programa é bem sucedido, tanto em Potsdam como em outras universidades.

No entanto, é importante destacar problemas que dificultam a integração dos refugiados nos estudos universitários e que precisam ser levados em conta. Participantes dos países árabes estão acostumados a uma cultura de aprendizado completamente diferente. Em seus países de origem, um palestrante transmite o material de aprendizagem, os estudantes o memorizam e não questionam. Nas universidades alemãs, ensinam-se diferentes aspectos que precisam ser discutidos e avaliados. Esta didática é muito confusa para os participantes e eles frequentemente perguntam: "qual é a verdade, o que devo escrever?". O mesmo acontece nos exames de idiomas, em que o aluno deve discutir as vantagens e desvantagens dos respectivos temas. Muitos refugiados fracassam, porque não têm experiência com discussões controversas. Do ponto de vista das universidades alemãs, estas pessoas ainda não são aptas para o ensino superior, por não terem acesso ao pensamento científico (embora muitos já tenham estudado na Síria). As diferenças culturais exigem muita empatia e paciência de ambos os lados.

Outra dificuldade a ser considerada é a maneira pela qual essas pessoas podem superar o trauma da guerra e dos sofrimentos, durante a fuga. Muitos refugiados estão traumatizados pelas experiências extremas às quais foram expostas. Isso, frequentemente, prejudica sua capacidade de estudar e trabalhar. As instituições de ensino superior têm que avaliar com muita delicadeza e pensar até que ponto condições psicossociais especiais podem ser levadas em conta, sem negligenciar as exigências formais do estudo.

Após a prontidão eufórica de apoio aos refugiados, no início, os atores sociais envolvidos estão agora compreendendo, cada vez 
mais, que a integração de refugiados se trata de um caminho difícil, desgastante e demorado. De um lado, isso levou a uma profissionalização do trabalho, ou seja, hoje há funcionários qualificados que são pagos para os seus serviços. Por outro lado, a proporção de ajudantes voluntários está diminuindo. O mesmo acontece com os estudantes à disposição de se envolverem com os colegas refugiados, cuja quantidade diminuiu.

Este é um desenvolvimento que se percebe também em outras áreas da sociedade. De um lado, existe hoje em dia um trato profissional e competente com os assuntos de integração dos refugiados e se criam gabinetes especiais para este fim. Por outro lado, há um declínio no trabalho voluntário. Mesmo assim, há ainda uma sólida percentagem de pessoas que se engajam pessoalmente em favor dos refugiados. No entanto, há também grupos de pessoas que se expressam, de maneira cada vez mais barulhenta, contra a presença de refugiados.

Concluindo, gostaria de discutir a crescente divisão da sociedade europeia.

\section{PERSPECTIVAS: NÓS E VOCÊS}

"O conseguiremos", a expressão famosa da chanceler federal alemã, refletiu, em 2015, os sentimentos de muitas pessoas. Parecia que havia uma tarefa comum para o nosso país. Era um estado de emergência, com um senso de comunidade envolvente. Para muitas pessoas, era importante a imagem de um país cosmopolita, tolerante e acolhedor, para que os refugiados se sentissem em casa.

Após três anos, a situação mudou significativamente. O nós acolhedor transformou-se em vários nós, precisando de vocês para estabelecer limites. Este desenvolvimento pode ser observado em muitos países, especialmente no Reino Unido, onde o Brexit provocou uma polarização na qual os dois lados são irreconciliavelmente opostos, não há entendimento comum e nenhuma ponte para facilitar o reconhecimento mútuo.

Alguns sociólogos também falam em uma crescente tribalização (termo originalmente usada para descrever culturas juvenis) 
das sociedades ocidentais. Isso se refere à formação de códigos culturais delimitadores, sem nenhuma moderação mediante a relativização da própria posição. Ao contrário, a própria percepção do mundo se torna o único padrão de julgamento.

Na discussão alemã sobre migração e imigração, podem-se observar três sistemas de ressonância que são predominantemente negativos e se delimitam mutuamente. Vou caracterizá-los brevemente e, na última parte, esboçar abordagens para superar os bloqueios mútuos.

\subsection{NENHUM SER HUMANO É ILEGAL}

A partir da grande cultura acolhedora do nós, surgiu um grupo radical de apoiadores de um mundo sem fronteiras, que representa a forte posição moral que se deve ajudar a pessoas necessitadas. Embora essa atitude tenha sido bem recebida quanto aos refugiados da guerra civil da Síria, a situação é diferente em relação aos refugiados dos países africanos, onde as razões para a fuga são diversas e fortemente relacionadas com a miséria econômica. Além disso, a migração de países africanos parece ser um "poço sem fundo", pois o número de refugiados da África é incalculável; enquanto se torna admissível lidar com os refugiados sírios, embora em grande número, pois são pessoas que poderiam vir até nós.

A UE está fortemente expandindo a proteção das suas fronteiras externas, empregando, para isso, a sua própria polícia europeia. Milhares de pessoas estão se afogando no Mediterrâneo, tentando chegar à Europa, em pequenos barcos. Em contraste, ativistas de muitas regiões europeias operam serviços de resgate com seus próprios navios. Para isso, eles coletam doações e recebem apoio, através de eventos e manifestações na Alemanha e em outros países. Ao mesmo tempo, a Itália e outros países procuram impedir que os navios com refugiados atraquem em seus portos e tratam as ações dos socorristas como ilegais.

Ativistas que se engajam para a humanização da política de refugiados querem impedir que a Europa se isole destas pessoas. Eles exigem que se criem possibilidades seguras para a entrada 
na Europa e para o reconhecimento dos refugiados. Dizem que a Europa é, em grande parte, responsável pelas miseráveis condições de vida de muitas regiões africanas, devido à política colonial e à exploração, que ocorre até hoje dos seus recursos naturais. Segundo eles, não deve haver limitação das migrações e das fugas do continente africano. Outro campo de ação é a proteção de refugiados cujo pedido de asilo foi negado e que devem retornar aos seus países de origem. Há pessoas que ajudam esses refugiados a usufruírem das medidas legais existentes ou até a se esconderem da lei.

\subsection{ESCASSEZ DE TRABALHADORES QUALIFICADOS}

Como já na década de 1960, a economia alemã está precisando atualmente de trabalhadores qualificados e não há o número suficiente deles para suprir a demanda. Devido às baixas taxas de natalidade, o número de pessoas em idade para trabalhar continua diminuindo. São necessários imigrantes altamente qualificados e especialistas em Tecnologia de Informática (TI), bem como pessoal de enfermagem, de gastronomia, etc.

Segundo cálculos de institutos econômicos, mais de 200 mil pessoas teriam que imigrar para a Alemanha a cada ano. Representantes de associações empresariais vêm pedindo há muito tempo uma lei de imigração que identifique critérios de imigração semelhantes aos do sistema de pontuação do Canadá. Aqueles refugiados que foram contratados por tempo indefinido, devem ter direito permanente de residência. Argumenta-se que é do interesse da economia alemã recrutar ativamente imigrantes. Esta é a única maneira de garantir o crescimento econômico, a competitividade e a prosperidade no futuro. Ao mesmo tempo em que se devem recrutar pessoas que possam ser facilmente integradas na economia, não se deve excluir aquelas que não estão aptas para o trabalho. Para este fim, o Governo Federal, atualmente, está preparando uma lei sobre imigração legal. Paralelamente, haverá também uma lei para facilitar o retorno de refugiados não reconhecidos aos seus países. 


\subsection{XENOFOBIA}

Em contraste com as duas posições apresentadas acima, há uma parte da população, inclusive pessoas organizadas em partidos e associações, que querem reduzir o número de estrangeiros no país, fazendo retornar o maior número possível de refugiados aos seus países de origem, defendendo o fechamento das fronteiras para todo tipo de refugiado. Estas pessoas falam do medo de se chegar a ter mais estrangeiros do que nativos no país e da perda da identidade cultural ou da independência da Alemanha. Querem evitar a construção de mesquitas, para que não haja "islamização" do país. Há cálculos absurdos que predizem que, devido ao grande número de filhos, a população muçulmana, em apenas poucas décadas, superaria os alemães em seu próprio país.

Esta ideia está ligada à rejeição de instituições supranacionais como a UE e ao desejo de retorno do Estado soberano, do Estado-nação. As pessoas que pensam isso sentem nostalgia por tempos passados, que, supostamente, eram melhores e mais fáceis. Rejeitam uma sociedade aberta e individualizada. Criticam a orientação sexual das pessoas e o direito de adoção por casais de gays e lésbicas. Elas declaram a norma social como sendo a família tradicional formada por homens e mulheres com filhos, enquanto que todas as outras formas de união são consideradas anormais. Na maioria dos países europeus, hoje em dia, existem partidos nacionalistas e movimentos raciais latentes, obtendo em seu favor de $20 \%$ a 30\% nos resultados das eleições.

\section{CONSIDERAÇÕES FINAIS}

A divisão da sociedade europeia e da Alemanha é intolerável e prejudicial ao desenvolvimento pacífico e à qualidade de vida das pessoas. Por conseguinte, é desafio-chave agora voltar a uma política do nós, sem que este conceito negue que existam diferentes estilos de vida. O primeiro requisito é relativizar a própria visão do mundo e permitir a existência de outras posições, aceitando as opiniões de uns e de outros.

Para a economia e sua necessidade de mão de obra, deve ser muito fácil adotar um pensamento de abertura. Empresas só 
podem atrair trabalhadores estrangeiros, se o ambiente de vida for adequado para estes funcionários. Quando havia manifestações xenófobas acontecendo, todas as semanas, na cidade de Dresden, a universidade e as empresas locais temiam por suas chances de atrair funcionários estrangeiros. As empresas, por interesse próprio, precisam convencer as pessoas de orientação nacionalista de que ser cosmopolita é do interesse da nação. Muitas empresas já apoiam esse movimento de abertura ativamente, com dinheiro, discursos e campanhas para que sua respectiva região, ou a Alemanha como todo, seja cosmopolita. Para a economia, também faz sentido essa postura cosmopolita, por outra razão: relativizar o ponto de vista puramente funcional com respeito à imigração. Ou seja, ter responsabilidade humanitária e equilíbrio social é essencial para uma sociedade pacífica e resiliente. O modelo de sucesso da economia social de mercado, praticado na Alemanha, é prova disso.

Já para os representantes de um humanismo radical, é mais difícil aceitar que é necessário colocar certos limites à imigração. Sua convicção lhes traz consequências para o próprio modo de vida. Esse poderia ser o ponto de partida: uma prática radical pode melhorar apenas uma pequena parte do mundo. Se, por exemplo, um grupo trabalha para o resgate de náufragos no Mediterrâneo, esta ação é, ao mesmo tempo, consistente e limitada. Houve e ainda há muito compromisso e dedicação para com os refugiados da guerra civil na Síria. Porém, ao mesmo tempo, há outras guerras muito cruéis acontecendo, como no Iêmen. Nenhum refugiado pode chegar do Iêmen até à Europa, ninguém é salvo e deixamos isso acontecer. Temos que viver com este realismo moral.

Quanto aos movimentos mais nacionalistas e racistas, relativizar a própria visão do mundo parece impossível. Onde há agressão e destruição (até mesmo autodestruição), a pacificação é dificilmente possível. Perto destes movimentos, no entanto, encontram-se pessoas que apenas sentem medo de mudanças e da dinâmica de processos dificilmente influenciáveis, nas suas vidas pessoais e comunitárias. Para estas pessoas que se percebem como indefesas, rejeitar imigrantes serve, muitas vezes, apenas como para-raios. Existem pessoas com outras orientações políticas que até 
compartilham parte destas preocupações, o que abre possibilidades para o diálogo.

O modo mais óbvio e eficaz de relativizar uma atitude xenófoba é o hábito. Pesquisas sobre atitudes xenófobas mostram que pessoas de regiões onde há poucos estrangeiros estão mais preocupadas e com medo de pessoas de fora, do que pessoas que vivem em áreas onde muitas nacionalidades estão presentes. Há regiões no sul da Alemanha, onde, desde a chegada dos chamados trabalhadores convidados, 60 anos atrás, os nativos simplesmente se acostumaram à vida lado a lado com os imigrantes e não há necessidade de treinamento intercultural para perceber que os vizinhos estrangeiros são pessoas absolutamente normais. 